\title{
Review
}

\section{NEW TRENDS IN TERAHERTZ ELECTRONICS}

\author{
V. Tamošiūnas a ${ }^{a}$, D. Seliuta ${ }^{a}$, A. Juozapavičius ${ }^{a}$, E. Širmulis ${ }^{a}$, G. Valušis ${ }^{\text {a }}$, \\ A. El Fatimy ${ }^{\text {b }}$, Y. Meziani ${ }^{\text {b }}$, N. Dyakonova ${ }^{\text {b }}$, J. Lusakowski ${ }^{\text {b }}$, W. Knap ${ }^{\text {b }}$, \\ A. Lisauskas ${ }^{\mathrm{c}}$, H.G. Roskos ${ }^{\mathrm{c}}$, and K. Köhler ${ }^{\mathrm{d}}$

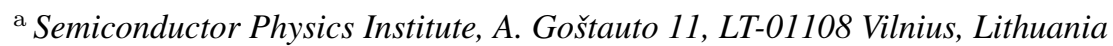 \\ E-mail: valusis@pfi.lt \\ ${ }^{\mathrm{b}}$ GES-UMR 5650 CNRS Universite Montpellier 2, 34900 Montpellier, France \\ ${ }^{c}$ Physikalisches Institut, Johann Wolfgang Goethe-Universität, Max-von-Laue-Strasse 1, D-60438 Frankfurt/M, Germany \\ ${ }^{\mathrm{d}}$ Fraunhofer-Institut für Angewandte Festkörperphysik, Tullastr. 72, D-79108 Freiburg, Germany
}

Received 14 March 2006

Dedicated to academician Juras Požela on the occasion of his 80th birthday

\begin{abstract}
The rapid evolution of terahertz (THz) applications in imaging, material diagnostics, communication systems, etc. stimulates an intensive search for new solutions in design and fabrication of compact emitters and receivers. The particular place of THz range in the electromagnetic spectrum - between microwaves and the infrared one - defines the requirement to merge together different concepts in the development of devices for THz electronics needs. The present overview covers several new topics illustrating unprecedented possibilities of modern semiconductor nanotechnology to realize innovative compact devices for terahertz electronics. We describe operation principles of quantum cascade lasers (QCLs) giving special emphasis to the specifics of THz quantum cascade devices and obstacles in their development. As an illustration of successful confluence of different physical approaches, we report on semiconductor nanostructure-based THz sensors - nanometric field effect transistors and asymmetric bow-tie diodes containing two-dimensional electron gas - which can successfully be employed for selective / broadband detection of the $\mathrm{THz}$ radiation.
\end{abstract}

Keywords: THz frequencies, quantum cascade lasers, two-dimensional electron gas, nanometric field effect transistors, asymmetric bow-tie diodes, plasma waves, non-uniform electron heating

PACS: 72.30.+q, 73,21.Fg, 73.61.Ey, 73,63.Hs

\section{Introduction}

The frequency range between $10^{11}$ and $10^{13} \mathrm{~Hz}$ or the so-called $\mathrm{THz}\left(1 \mathrm{THz}=10^{12} \mathrm{~Hz}\right)$ frequencies (corresponding energies are $0.4-40 \mathrm{meV}$; the wavelength range is $3000-30 \mu \mathrm{m}$ or, in wavenumbers, $3.33-333 \mathrm{~cm}^{-1}$ ) remains among the most undeveloped regions in the electromagnetic radiation scale. A large variety of potential applications in many fields non-invasive material diagnostics and broad bandwidth communication systems; detection of chemical compounds and biological agents; usage of $\mathrm{THz}$ imaging in medicine and for security purposes, etc. - has stimulated an intensive burst of research oriented to create compact $\mathrm{THz}$ emitters and receivers. The lack of such electrically-driven solid-state $\mathrm{THz}$ emission sources and relevant sensors was the main obstacle preventing versatile practical implementation of the $\mathrm{THz}$ radiation. This complication is related to the specific place of the THz range in the electromagnetic radiation scale - it falls between the millimetre waves and the infrared region. From the point of view of device physics, a classical carrier transport is employed in the millimetre waves, and the cut-off frequency of these devices is mainly limited by carrier transit time or parasitic $R C$ time constants. In contrast to electronic devices, photonic devices avoid these restrictions. However, since they utilize charge carrier transitions, operation range is defined by an energy band gap of semiconductor. In frequency domain, even for narrow-gap semiconductors, possible emission frequency does not reach below $10 \mathrm{THz}$. Therefore, new approaches should be applied to "bridge" the $\mathrm{THz}$ range.

In 1989, academician Juras Požela considered a diagram (Fig. 1) in which he predicted several different mechanisms that can be used to cover the $\mathrm{THz}$ frequencies using solid-state sources [1]. According to his 


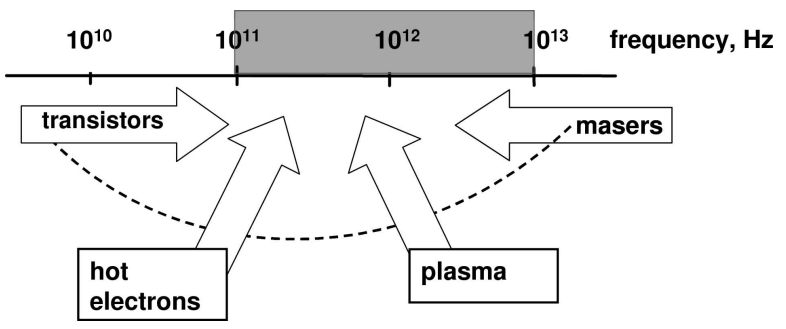

Fig. 1. Main directions to cover the frequency band from $10^{11}$ to $10^{13} \mathrm{~Hz}$ by using solid state sources (according to Juras Požela [1], p. 248).

predictions, transistors and hot electron effects can be used from the "red side" of the range, plasma phenomena are the most suitable for the range around $1 \mathrm{THz}$, meanwhile the laser approach, i.e. carrier transition effects can be applied from the higher energy side the "blue side". As the frequency range below $10 \mathrm{THz}$ cannot be generated using conventional semiconductor diode lasers, new materials should be found or artificially fabricated to reach this aim.

Invention of molecular beam epitaxy (MBE) [2] has opened unprecedented possibilities to make artificial semiconductor materials with desired features. These so-called materials by design consist of series of alternating semiconductor nanolayers (quantum wells), and their properties are defined more by the design of the structure (layer thickness, doping profile, etc.) than by the material itself. Such an approach allows one to fabricate quantum mechanical systems in which the energy levels can be designed and engineered to any value. Consequently, devices based on intersubband transitions (for instance, an electron emits or absorbs a photon using transitions between subband levels within the conduction band) can be fabricated for the $\mathrm{THz}$ frequency range. However, as a rule, any single approach - e.g., quantum mechanical alone - does not help solving the problems in $\mathrm{THz}$ range, and, therefore, additional measures from other physical areas should be employed. For instance, to guide the radiation out of the active quantum structure or to couple it into the device it is necessary to use a waveguide or an antenna of a special design. In other words, fabrication of devices of $\mathrm{THz}$ frequencies requires confluence of different physical approaches and innovative engineering decisions.

In this paper, - via the specifics of design and operation of both emitters and detectors - we illustrate the possibilities of modern semiconductor nanotechnology together with waveguide and antennae approach to realize innovative compact devices for terahertz electronics. The article is organized as follows. Section 2 is

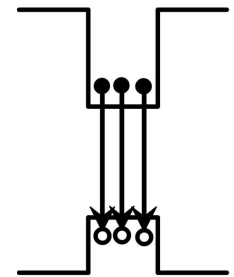

Interband

Laser

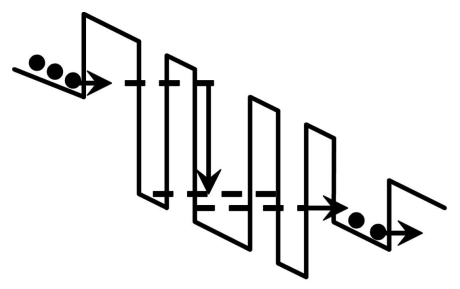

Intersubband

Laser
Fig. 2. Operation principles of interband and intersubband lasers. In the first case, a photon is emitted as a consequence of electron "jump" into the valence band; the photon energies are equal to or greater than $E_{\mathrm{g}}$. In the case of the intersubband laser, "jumps" between the engineered energy levels in conduction band are employed, where one electron may emit multiple photons while crossing multiple cascades of the active region ( 1 photon per cascade in an ideal case).

devoted to the description of quantum cascade lasers (QCLs) and specifics in their development for $\mathrm{THz}$ frequencies. In Section 3 we report on semiconductor nanostructure-based THz sensors - nanometric field effect transistors employing plasma waves for selective $\mathrm{THz}$ sensing, while in Section 4 we review bow-tie diodes containing two-dimensional electron gas, fabricated for broadband detection of $\mathrm{THz}$ radiation. In Conclusions we summarize the state of the art of the dominating compact solid-state-based devices - both emitters and detectors - in the context of the prediction diagram by Juras Požela made nearly two decades ago.

\section{Quantum cascade lasers}

As it is known, in conventional lasers, the light is emitted during the process of electron-hole recombination (Fig. 2(a)), while its wavelength is determined by the energy separation between the semiconductor conductance and valence bands. In QCLs, in contrast, no carrier recombination processes are involved - one employs electron transitions between bound states of semiconductor heterostructure (Fig. 2(b)), i. e., a QCL is a novel semiconductor laser in which only one type of carriers is participating. This heterostructure is a semiconductor quantum well $(\mathrm{QW})$ having the width comparable to the de Broglie wavelength. As a result, electron motion is restricted in perpendicular to the layers direction, and only electron "jumps" between the states with discrete energy levels of the heterostructure become possible. In such system, laser wavelength becomes dependent on the thicknesses of the heterostruc- 
ture layers and is not strictly defined by the semiconductor band gap anymore. In addition, multiple photons can be emitted by a single electron, since no recombination is employed, and the QW period can be repeated hundreds of times during the growth.

The first quantum cascade laser operating in infrared range was designed and fabricated by Faist and $\mathrm{Ca}-$ passo at Bell Labs [3]. This invention has stimulated huge burst of research in order to find optimal design and materials for infrared lasing, to increase the emission wavelength, and to use the QCLs for various application purposes (see, e.g., reviews $[4,5]$ ). It is worth mentioning several interesting approaches based on quantum cascade scheme of operation such as quantum cascade disk lasers [6], high power directional emission from microlasers with chaotic resonators [7], single mode surface plasmon lasers [8], and application of photonic crystals to guide the emission modes through the surface of the device [9]. The main challenge among the variety of obstacles in QCL development has remained to extend the operation to the far infrared (or $\mathrm{THz}$ ) range, i. e., below the Reststrahlen band which is between 8 and $9 \mathrm{THz}$ in GaAs. There were three main problems preventing the achievement of this goal:

- The first one was related to the energy level separation: it is rather small in the $\mathrm{THz}$ range - for example, within 10-20 meV for corresponding 2.4$4.9 \mathrm{THz}$ frequencies - therefore the selective depopulation mechanism based on energy-sensitive longitudinal optical (LO) phonon scattering, which is successfully implemented in infrared QCLs, is not suitable.

- The second problem was associated with the low loss optical mode confinement, which is essential for any laser action. In infrared QCLs, as a rule, conventional dielectric waveguide confinement is used which cannot be applied in the $\mathrm{THz}$ range due to the large size of the optical mode (imposed by the wavelength) extending to the order of several tens of micrometres. Since the evanescent field penetration is proportional to the wavelength, it is much larger compared to the active gain medium - its size in QCLs amounts to only several micrometres.

- Finally, it was necessary to overcome high intrinsic optical losses induced by free electrons in the structure which scale as wavelength squared.

These obstacles were successfully overcome, and the operation of the first $\mathrm{THz}$ QCL was demonstrated by the Pisa group [10]. Before proceeding to the description of the device, we briefly recall the principles of material design usually applied in constructing devices based on semiconductor quantum structures.

Energy levels (or electronic eigenenergies) of a QW can be engineered by selecting the appropriate layer thicknesses using modern band structure computation techniques. In the most simple case, it requires a solution of a one-dimensional Schrödinger equation in the envelope function approximation:

$$
\left[-\frac{\hbar^{2}}{2} \frac{\mathrm{d}}{\mathrm{d} z}\left(\frac{1}{m_{0}^{*}(z)} \frac{\mathrm{d}}{\mathrm{d} z}\right)+V(z)\right] \Phi(z)=E_{n} \Phi_{n}(z),
$$

here $z$ indicates the growth direction, $\phi(z)$ is the slowly varying envelope wavefunction, $E_{n}$ is the eigenenergy of the $n$th state, $m_{0}^{*}(z)$ is an effective mass of the electron, $V(z)$ is potential, $\hbar$ is the Planck constant. A complete wavefunction also has an $x, y$-dependent part $\exp \left(\mathrm{i} k_{x} x+\mathrm{i} k_{y} y\right)$ and a fast-varying Bloch part $u_{c}(x, y, z)$, which "shares" the periodicity of the crystal lattice:

$$
\Psi(x, y, z)=u_{c}(x, y, z) \frac{\exp \left(\mathrm{i} k_{x} x+\mathrm{i} k_{y} y\right)}{\sqrt{A}} \Phi(z) .
$$

Equation (1) can relatively easily be solved for several best known cases, such as square quantum well with finite / infinite barrier height or parabolic quantum well. However, a more complex approach is required for the case of an arbitrary potential $V(z)$. Luckily, this arbitrary potential can nearly always be approximated with a sufficient precision by a stepwise constant potential if $z$ axis is subdivided into $N$ sufficiently thin layers, the $j$ th of which has a constant potential $V_{j}$. In such case, the Schrödinger equation for the $j$ th layer becomes

$$
\left(-\frac{\hbar^{2}}{2 m_{j}^{*}} \frac{\mathrm{d}^{2}}{\mathrm{~d} z^{2}}+V_{j}\right) \Phi_{j}(z)=E \Phi_{j}(z)
$$

with the well-known solution for $z_{j-1} \leq z \leq z_{j}$ range, $\Phi_{j}(z)=A_{j} \exp \left[\mathrm{i} k_{j}\left(z-z_{j}\right)\right]+B_{j} \exp \left[-\mathrm{i} k_{j}\left(z-z_{j}\right)\right]$,

and with the corresponding wavenumber

$$
k_{j}=\sqrt{\frac{2 m_{j}^{*}}{\hbar^{2}}\left(E-V_{j}\right)} .
$$

Boundary conditions for each "interface" between $N$ layers are obtained from the continuity requirement for $\Phi(z)$ and $1 / m_{0}^{*}(z) \cdot \mathrm{d} \Phi(z) / \mathrm{d} z$, giving two equations relating $A_{j}, B_{j}$ and $A_{j+1}, B_{j+1}$. In addition, it is usually assumed that wavefunctions in the regions 0 and $N+1$ must be decaying, leading to $A_{0}=0$ and $B_{N+1}=0$, 


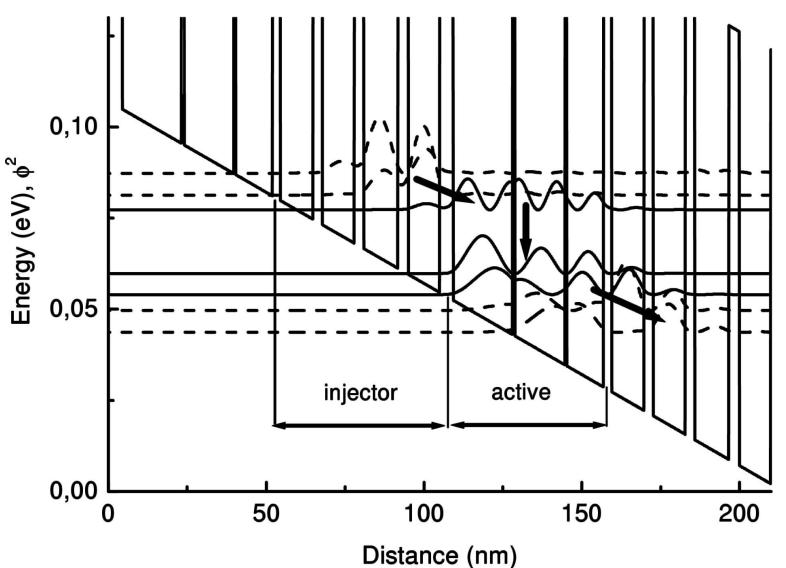

Fig. 3. Computed energy levels in $\mathrm{THz}$ quantum cascade laser of type given in Ref. [10]. One cascade of the QCL consists of seven coupled quantum wells: four wells form an injector stage, while three wider wells - an active region. The photon emission occurs when an electron "jumps" between two states with $\sim 18.6 \mathrm{meV}$ separation, while "the ladder" of closely positioned states (with typical spacing of $\sim 3-5 \mathrm{meV}$ ) ensures that electrons are quickly extracted from the lower state of laser transitions and moved to the upper state of laser transition of the next cascade.

and, therefore, a sufficient number of equations is obtained for the solution on the personal computer.

Results of such computations for the first $\mathrm{THz}$ quantum cascade laser [10] are presented in Fig. 3. The lasing structure is composed of a four-quantum-well injector part and a three-well active region. Such layout ensures that energy levels in the injector are placed closely enough to ensure a fast extraction of electrons from the lower laser state of $18.6 \mathrm{meV}$ transition and an efficient "supply" into the upper level of the next cascade segment. To maintain the necessary carrier population inversion, Tredicucci and co-workers [10] dilated the total carrier population over the 104 periods of the quantum structures. In addition, it also allowed to reduce significantly the optical losses. This way, the gain of such THz QCL becomes comparable to that of a conventional laser diode. However, its value is two orders of magnitude lower per period of the structure.

Later, $\mathrm{Hu}$ with co-workers from the Massachusetts Institute of Technology (MIT) group has suggested a new design [11] which enabled to use LO phonon emission to depopulate fast the lower state in the active region and "to engineer" thus the lifetimes in a suitable for lasing manner. In this case, the active region is composed of four quantum wells, while the inherent feature of injector design is a much larger spacing between the levels - it exceeds the optical phonon value of $36 \mathrm{meV}$ in GaAs.

To tackle the problem of waveguiding in THz QCLs, the hybrid concept of "metallic microwave strip line"

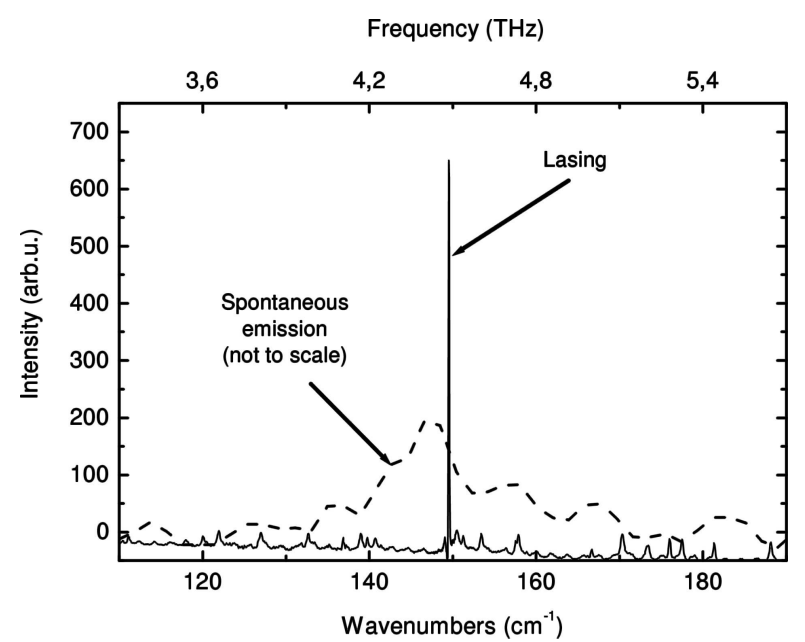

Fig. 4. Emission spectra of the THz QCL of the design given in Ref. [10]. The dashed line shows the emission spectrum of the QCL operating below the threshold, recorded at $4 \mathrm{~cm}^{-1}$ resolution using FTIR spectrometer in a step scan mode with lock-in amplifier. The continuous line depicts the emission spectrum of the QCL operating above the threshold, recorded at $0.125 \mathrm{~cm}^{-1}$ resolution in a continuous scan FTIR spectrometer mode.

and "surface plasmon waveguide" [12] - the approach which works nicely in the infrared range - was implemented. The generated $\mathrm{THz}$ mode is guided in a delicate manner - the highly absorbing layer of heavily doped semiconductor separates the mode so that only half of it remains in the active region, while the residual part is kept in a low-losses substrate [10]. Later, the other method to waveguide $\mathrm{THz}$ modes delivered by the THz QCL was developed - the same MIT group suggested a double-sided metal-metal waveguide for mode confinement, or the so-called double metal approach [13]. This enabled them to achieve the mode confinement factor close to 1 instead of 0.47 in the "surface plasmon waveguide" [10]. Subsequently, the operation of $\mathrm{THz}$ QCLs was strongly improved allowing one to reach several records such as the lowest emission frequency of $2.1 \mathrm{THz}$ [14], first continuous wave $\mathrm{THz}$ QCL operating above the important liquid nitrogen temperature [15], highest operation temperature in pulsed mode [16], and realization of $\mathrm{THz}$ microcavity QCL [17].

Emission spectra of a typical $\mathrm{THz}$ quantum cascade laser are presented in Fig. 4. A broad $\left(\sim 10 \mathrm{~cm}^{-1}\right.$ wide) electroluminescence spectrum is observed when the current is approaching the threshold, but that is still insufficient for the laser operation (dashed line). Once the threshold is achieved, emission intensity increases by several orders of magnitude, while the emission line width decreases below the resolution limits of the spectrometer. 
System used in the emission experiments consisted of a Fourier transform infrared (FTIR) spectrometer (NICOLET Magna IR 850) equipped with a Si beamsplitter and a $4.2 \mathrm{~K} \mathrm{Si}$ bolometer as in Ref. [18]. A 4.5 THz QCL based on the active structure design proposed in [10] was used for the measurements. The device consists of 100 periods of the active structure sandwiched between two $n^{+}$-doped contact layers (the bottom layer was $d=500 \mathrm{~nm}$ thick with $n=4 \cdot 10^{18} \mathrm{~cm}^{-3}$ doping, the top layer was $d=100 \mathrm{~nm}$ thick with $n=$ $7 \cdot 10^{18} \mathrm{~cm}^{-3}$ doping) grown on a semi-insulating GaAs substrate using the MBE technique. The laser devices were processed as ridges of lateral dimensions of $130 \mu \mathrm{m}$ by reactive ion etching through the active zone down to the bottom contact layer. Metallic contacts $(15 \mathrm{~nm} / 30 \mathrm{~nm} / 14 \mathrm{~nm} / 200 \mathrm{~nm}$ of $\mathrm{Ge} / \mathrm{Au} / \mathrm{Ni} / \mathrm{Au})$ were evaporated for the bottom contact layer with approximately $10 \mu \mathrm{m}$ separation from the ridge. Two $10 \mu \mathrm{m}$ wide contact stripes of the same composition were evaporated on top of the ridge with $5 \mu \mathrm{m}$ separation from the side walls. The sample was then annealed for $1 \mathrm{~min}$ at $430^{\circ} \mathrm{C}$ to alloy the ohmic contacts. Afterwards, $10 \mathrm{~nm} / 400 \mathrm{~nm} \mathrm{Ti} /$ Au layers were sputtered on top of the ridge to finish the top contact and to provide wave guiding. The sample was cleaved into $3 \mathrm{~mm}$ long devices, soldered with indium onto a copper holder and wire bonded.

In these devices the "surface plasmon waveguide" concept was used. The physics behind the operation is that the dielectric constant of the heavily doped $n^{+}$ layer can be made negative, but still comparable in modulus to the dielectric constant of the surrounding semiconductor by proper selection of the doping density. Once the thickness of the $n^{+}$layer decreases, two surface plasmons on interfaces with the outside semiconductor actually merge into a single mode [10] with an intensity maximum near the $n^{+}$layer and a rapidly decaying intensity further from it. Therefore, a very tight confinement of the mode may be achieved once laser heterostructure is grown in between the two $n^{+}$ layers with carefully selected parameters. Mode profiles for two waveguide designs are depicted in Fig. 5. As one can clearly see from this picture, larger electric field amplitude in the active region and a faster amplitude decay in the substrate are achieved, when a thicker top $n^{+}$layer is considered, resulting in a larger confinement factor and lower gain required for operation.

As a rule, ridge-shaped Fabry-Perot resonators are the most common ones for THz QCLs. However, it happens quite often that the gain of the active region is insufficient to support a quite large energy loss when

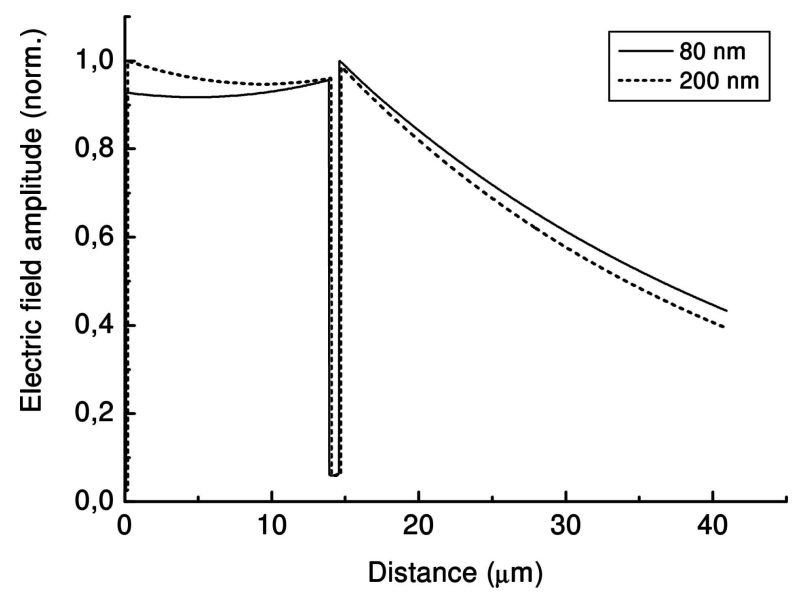

Fig. 5. Simulated mode profiles (plotted: normalized electric field amplitude versus the distance from the upper contact) within two QCLs operating at $3.5 \mathrm{THz}$. A finite-difference time-domain (FDTD) simulation was employed to obtain these profiles. In both cases "wide device" (in comparison to wavelength) approximation was considered for two lasers with the same $13.8 \mu \mathrm{m}$ thick active region (gain maximum at $3.5 \mathrm{THz}$ ), the same bottom $n^{+}$layer (680 $\mathrm{nm}$ thick, $2 \cdot 10^{18} \mathrm{~cm}^{-3}$ doping), and two different top $n^{+}$layers (continuous line $-80 \mathrm{~nm}$ thick, dotted line $-200 \mathrm{~nm}$ thick, both doped by $5 \cdot 10^{18} \mathrm{~cm}^{-3}$ ). As one can clearly see, thicker $n^{+}$layer on top of the structure can be employed to increase the confinement factor (amplitude reduces faster in the substrate in the case of

$200 \mathrm{~nm}$ layer), which means an increased effective gain.

light is reflected from two facets of the resonator. Partially, this problem may be solved by reducing the thickness of the substrate or even removing it and increasing mode overlap with the active region (and the effective modal gain at the same time). The key decision helping in this situation is the already mentioned "double metal" QCL design [13]. In some cases, when (nearly) total internal reflection is required, a completely different design of QCLs is used. This may be efficiently achieved in ring / disk-shaped resonators, where the so-called whispering-gallery modes are obtained. Electric field amplitude for such mode within the disk-shaped QCL of $R=100 \mu \mathrm{m}$ radius is presented in Fig. 6. An electromagnetic wave of this mode always reaches the outer surface of the resonator at an angle exceeding the angle of the total internal reflection, therefore only minor losses occur. Emission of such a mode is observed mainly because of the surface irregularities of the resonator; therefore, it is not well suitable for direct applications requiring high output powers. On the other hand, it can serve as a beautiful example when lasing can be achieved in the low gain exhibiting materials.

Ending this section, it is reasonable to consider whether the quantum cascade structures can be used for the inverse task to the $\mathrm{THz}$ emission, i.e. for 


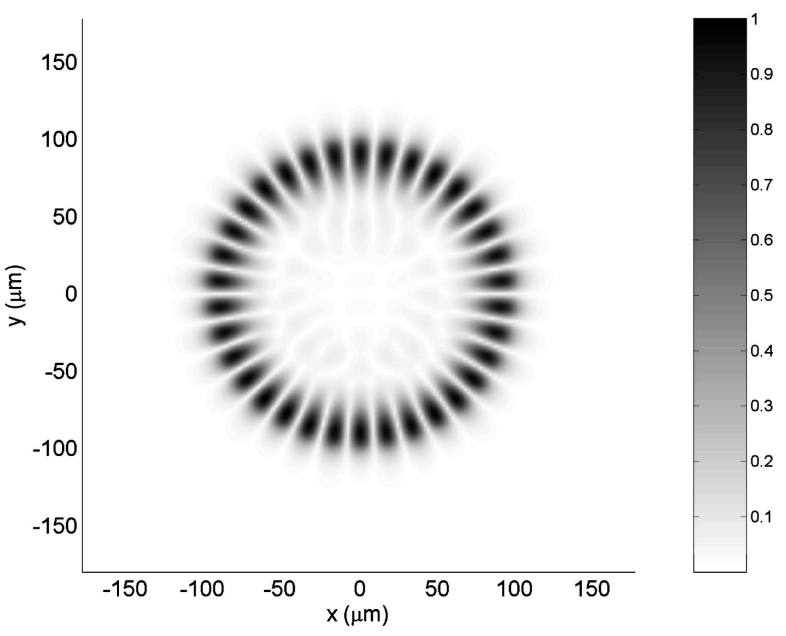

Fig. 6. Distribution of electric field amplitude within (and near) the $200 \mu \mathrm{m}$ wide and $14 \mu \mathrm{m}$ thick "double metal" disk QCL resonator. A finite-difference time-domain (FDTD) simulation was employed to obtain this profile for a mode emitting at $2.748 \mathrm{THz}$. Disk centre corresponds to coordinates $(0 ; 0)$. It is assumed that the disk is surrounded by $70 \mu \mathrm{m}$ of vacuum in each direction (with exception of bottom metal surface), terminated by absorbing boundaries, which permit a nearly non-reflecting propagation of outgoing waves. One can clearly see that at this frequency a so-called whispering gallery mode is formed, which "benefits" from low loss due to total internal reflections on the boundaries. Within this simulation, loss is not exactly zero, since surface roughness with detail size of $2 \mu \mathrm{m}$ was considered on the sidewalls and boundary of the top metal contact.

detection of THz frequencies. A study has shown [19] that, in principle, QCL-like structures can be used for this aim, however, their responsivity was found to be rather low, only of about $50 \mu \mathrm{A} / \mathrm{W}$ at $9.3 \mu \mathrm{m}$ wavelength at room temperature. In the $\mathrm{THz}$ range, the structures can also be used as sensors [20], but their operation, as in case of $\mathrm{THz}$ quantum well infrared photodetectors (QWIP) [21], is limited below $50 \mathrm{~K}$ due to strongly temperature-dependent nature of bound-tocontinuum transitions in these devices. For practical needs it would be very important to find other solutions that can be free from intersubband transition-based operation in emission / detection schemes. One of the possible options can be excitation of plasma waves in twodimensional electron gas (2DEG).

\section{Plasma waves in two-dimensional electron gas}

In 1993, Dyakonov and Shur considered 2DEG under gate (Fig. 7) in high electron mobility transistor (HEMT) [22]. They have shown that 2DEG behave as a fluid similar to a shallow water. The most important, under certain boundary conditions - when constant value of the voltage is applied at the source and constant value of the current is fixed on the drain -

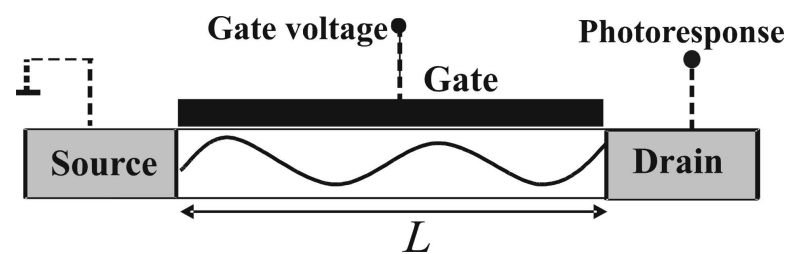

Fig. 7. Schematic view of the ballistic field effect transistor (according to Dyakonov-Shur [22]). The gate length is much smaller than the mean free path of electrons. Dashed lines show measurement scheme: the photoresponse induced by incident $\mathrm{THz}$ radiation is measured as a function of the gate voltage.

the 2DEG flow should be unstable due to plasma wave excitation and amplification because of the reflection from the boundaries of the device. The DyakonovShur theory of "shallow water" instability gave several important results vital for practical applications:

- firstly, the same device can be used either in emission or detection mode;

- secondly, depending on the parameters of the transistor, both the emission and detection can be either non-resonant (spectrally broad) or resonant (spectrally narrow);

- thirdly, spectral features of the device can be tuned by varying the gate voltage;

- and, finally, the operation of plasma wave-based devices is free of any intrasubband transitions and is not limited to low temperatures.

The latter feature, together with the convenience of integration of the devices into electronic circuits offers highly promising perspectives for various practical implementations: for instance, in a development of compact $\mathrm{THz}$ spectroscopy, where usage of nanometric transistors would allow to avoid gratings and moving mirrors, i. e., the conventional means usually needed to perform spectral analysis.

The experimental confirmation of the DyakonovShur theory via detection of sub- $\mathrm{THz}$ and $\mathrm{THz}$ radiation by plasma waves in nanometric field-effect transistors [23-25] has stimulated an indefatigable impetus to search for new solutions in design and fabrication of plasma wave-based compact $\mathrm{THz}$ receivers and emitters. The detection by plasma waves was successful in GaAs / AlGaAs-based structures - in double QW [26] and single QW field effect transistors [27] and silicon nanotransitors with $30 \mathrm{~nm}$ gate length [28]. Very recently, experiments have shown the possibility to tune the detection mode from non-resonant to the resonant one [29] and to use it for detection of pulsed $\mathrm{THz}$ radiation [30]. The nanometric transistors were also found to be attractive sources of $\mathrm{GHz}-\mathrm{THz}$ emission - 
the frequency-tunable generation by plasma waves was successfully demonstrated in AlInAs [31,32] and AlGaN/GaN-based devices [33].

In this work, we concentrate ourselves into investigation of $50 \mathrm{~nm}$ gate length GaAs / AlInAs HEMT. The motivation for the choice of the material can be easily seen from the Dyakonov-Shur formula describing the resonant plasma frequency $[25,34]$ :

$$
f=\frac{1}{4 L} \sqrt{\frac{e\left(V_{\mathrm{g}}-V_{\mathrm{th}}\right)}{m^{*}}},
$$

where $L$ is the gate length, $V_{\mathrm{g}}$ labels gate-to-source voltage, $V_{\text {th }}$ designates the threshold voltage, while $m^{*}$ stands for the electron effective mass. Therefore, in order to shift the plasmon resonances into higher frequencies - up to now the maximum plasma resonant frequency recorded in GaAs / AlGaAs-based devices with $250 \mathrm{~nm}$ gate is $0.6 \mathrm{THz}[24,25]$ - it is necessary to reduce the length of the gate and to find the material with lower electron effective mass. Bearing in mind these facts, GaAs / AlInAs compounds seem to be a very good option - the electron effective mass here is $0.042 m$ ( $m$ denotes the electron mass), i. e. it is lower than in relevant value in GaAs $(0.067 \mathrm{~m})$; additionally, facilities of modern technology allow to produce this material-based transistors with the gate length of $50 \mathrm{~nm}$, i. e. significantly smaller than in GaAs-based devices.

The design of the studied GaAs / AlInAs HEMTs is given in Fig. 8 with relevant comments in the figure caption. The sample was mounted on a quartz plate to avoid any parasitic interferences and reflections, and it was then placed into closed-cycle helium cryostat behind the THz-radiation-transparent highpressure polyethylene window. The incident radiation of 5-10 $\mathrm{mW}$ (depending on the emission line) was focused into spot of about 1.2-1.5 mm diameter which was much larger than the gate length and the width of the device. No special coupling antennas were used, and the incident radiation was coupled to the device through the contact pads.

We have measured the photoresponse - THz-induced $\mathrm{dc}$ voltage - on the drain as a function of gate voltage under excitation by an optically pumped $\mathrm{THz}$ laser (the measurement scheme is depicted by the dashed lines in Fig. 7) by varying the temperature within $4-300 \mathrm{~K}$ range and the excitation frequency within $0.5-3.1 \mathrm{THz}$. To understand the motivation of such experimental ideology one must recall the criterion separating the nature of the resonant detection from the non-resonant one. The criterion is defined by a quality factor, namely, $\omega \cdot \tau$,

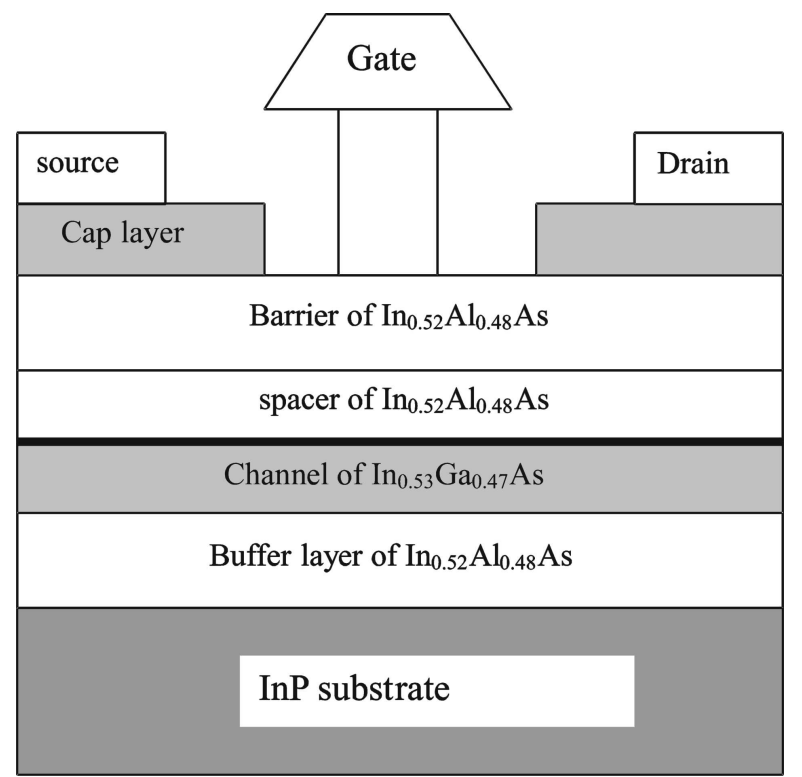

Fig. 8. InGaAs / AlInAs-based device with a T-shaped gate. The heterostructure was grown by MBE; the T-shaped gate was defined by electron beam lithography. The gate length is $50 \mathrm{~nm}$, its total width amounts to $50 \mu \mathrm{m}$. The cap layer is a $10 \mathrm{~nm}$ thick silicondoped $\left(6 \cdot 10^{18} \mathrm{~cm}^{-3}\right) \mathrm{In}_{0.53} \mathrm{Ga}_{0.47}$ As; the thick line depicts a silicon $\delta$-doping layer of $5 \cdot 10^{12} \mathrm{~cm}^{-2}$. The recess - the part of the device that is not covered by the heavily doped cap layer - is of $100 \mathrm{~nm}$ length on both sides of the gate. The distance between the source and the drain is $1.3 \mu \mathrm{m}$. The 2DEG concentration is about $3 \cdot 10^{11} \mathrm{~cm}^{-2}$ at $4.2 \mathrm{~K}$.

where $\omega=2 \pi f$, were $f$ is the excitation frequency, and $\tau$ denotes the electron momentum relaxation time. If the condition $\omega \cdot \tau<1$ is fulfilled, the plasma oscillations are overdamped, and, consequently, the response is a non-resonant one, exhibiting smooth function of frequency and gate voltage. In opposite case, when quality factor becomes much larger than 1 , the spectrally narrow plasmon resonance peak should be clearly resolved.

One can note that the latter condition can be achieved either by reducing $\tau$ via lowering the temperature or by increasing the excitation frequency. In what follows we have applied both approaches to evidence plasma wave related detection in two types of InGaAs/AlInAsbased devices. The threshold voltage was $0.75 \mathrm{~V}$ for the first type of devices and $0.47 \mathrm{~V}$ for the second one.

Figure 9 presents the results of the photoresponse measured in InGaAs / AlInAs nanotransistors of the first type. At room temperature no signal at $2.5 \mathrm{THz}$ is observed. However, as one can see, by lowering the temperature below $100 \mathrm{~K}$ the signal around the threshold voltage of the transistor appears and increases reaching its maximum at $10 \mathrm{~K}$. The observed photoresponse changes neither position nor spectral shape remaining spectrally broad, about $0.3 \mathrm{~V}$ of full width at 


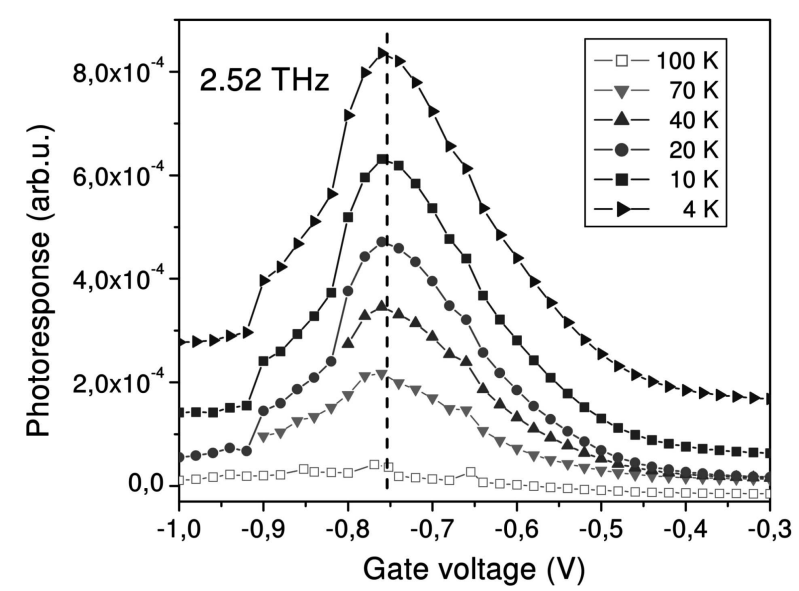

Fig. 9. Photoresponse in InGaAs / AlInAs-based device versus the gate voltage, illustrating the non-resonant detection of $\mathrm{THz}$ radiation.

half maximum, in all studied temperature range. According to theoretical considerations [25], all these features are inherent to non-resonant detection of the $\mathrm{THz}$ radiation by plasma waves. In contrast, the photoresponse in InGaAs / AlInAs nanotransistors of the second type depicted in Fig. 10 evolves differently with temperature. As it is seen from the top plot, below $50 \mathrm{~K}$, in addition to the temperature-independent peak around the threshold voltage of $-0.47 \mathrm{~V}$ (see bottom plot for the full curve), a shoulder from the lower voltage side in between -0.4 and $-0.3 \mathrm{~V}$ becomes visible. Further on, it develops to a clearly resolved temperature-sensitive peak at $10 \mathrm{~K}$. We attribute it to the plasma resonance. Indeed, knowing that the electron mobility is about $36000 \mathrm{~cm}^{2} /(\mathrm{V} \cdot \mathrm{s})$ at $60 \mathrm{~K}$ corresponding to the momentum relaxation time of $800 \mathrm{fs}$, one obtains the quality factor at $2.5 \mathrm{THz}$ equal to 13.4 , i. e., the criterion for the resonant plasma detection, $\omega \cdot \tau \gg 1$, is fully satisfied. To confirm the resonant origin of this peak, we have recorded the photoresponse data under excitation of different frequencies and compared the results with theoretical estimates obtained using formula (6). The data are given in the bottom plot. One can see that the photoresponse peak moves to the lower voltages with the increase of the excitation frequency up to $3.1 \mathrm{THz}$. If one compares the experimental plasma resonance frequencies with the corresponding calculated values (given in the inset), a reasonable agreement is found. It is worth noting, however, that the theoretical values of the plasmon resonances are slightly higher than those obtained experimentally. This peculiarity can be related to the presence of the recess in the structure - the part of the device that is not covered by the heavily doped cap layer - which was not taken into account. As concerns
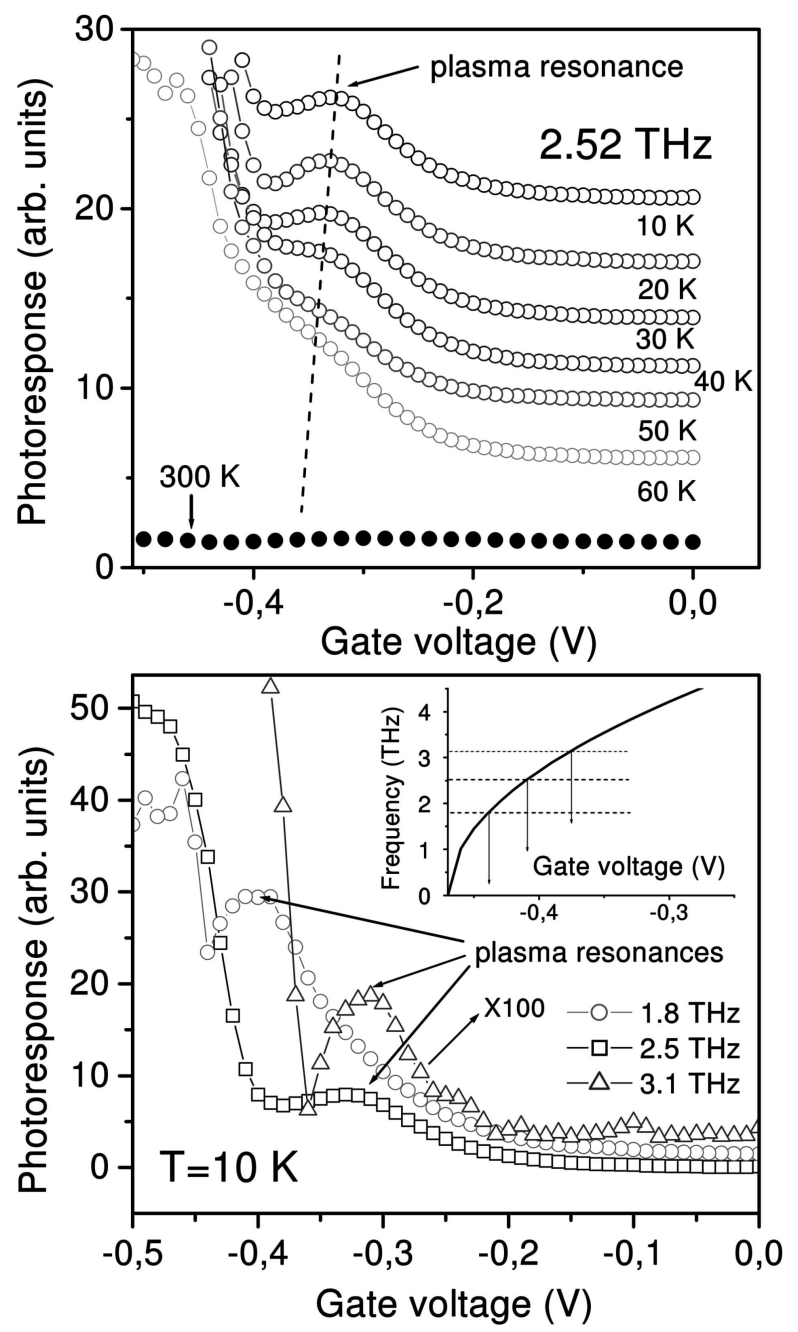

Fig. 10. Photoresponse in InGaAs / AlInAs-based device versus the gate voltage. Top plot: change with temperature at $2.5 \mathrm{THz}$. For the sake of clarity the curves are shifted in the vertical scale. The solid arrow shows the peak attributed to the non-resonant detection; the dashed line - a guide for an eye - is the evolution of plasmon resonance with temperature. Bottom plot: signal at different frequencies of THz excitation. Inset shows calculated plasmon frequency as a function of the gate voltage.

the temperature-independent peak around the threshold voltage of $-0.47 \mathrm{~V}$, as in previous case, we associate it with the non-resonant detection - we therefore omit the full curve since its behaviour is totally reproduced by the plot given in Fig. 9. Consequently, the usage of $50 \mathrm{~nm}$ gate length GaAs / AlInAs field effect transistors allows one to shift resonant detection by plasma waves into the $\mathrm{THz}$ range, to the frequency value of $3.1 \mathrm{THz}$ [35].

The experimental data reported here show that the semiconductor nanotransistors can serve as compact and gate voltage tunable sensors for broad band (nonresonant) and selective (resonant) $\mathrm{THz}$ detection. 
Sometimes, the integration of compact solid statebased sensors in semiconductor circuits requires other approach: it is very convenient in certain cases to use passive detectors instead of an active detection scheme. We further show how a confluence of semiconductor nanotechnology and antennae concept can help to design a new type of a sensor - the so-called 2DEG bowtie diode - which is well suited to detect $\mathrm{GHz}-\mathrm{THz}$ frequencies at room temperature.

\section{2DEG bow-tie diodes based on GaAs / AlGaAs modulation-doped structures}

Bow-tie antennae $[36,37]$ are very attractive ingredients in many sensing systems due to a relatively simple design and broad band impedance. In $\mathrm{THz}$ frequencies, such antennae can successfully serve as effective couplers of the incident radiation in various types of structures, for instance, like in GaAs / AlGaAsbased resonant tunnelling diodes [38] and high temperature superconductor-based bolometric detectors [39]; bow-tie antennae fabricated on low-temperature-grown GaAs can effectively be implemented for the coherent generation and detection of ultra-broadband $\mathrm{THz}$ radiation with frequency components extending to over $15 \mathrm{THz}$ [40].

In this work, we describe a new type of approach using the bow-tie antennae ideology: we have designed and fabricated a bow-tie-shaped sensor with 2DEG layer as an active component - so-called 2DEG bowtie diode. Its shape and design are presented in Fig. 11. As one can see, it represents the bow-tie antenna with a broken symmetry: one of its leaves (the upper) is metallized (dark coloured), while the other one (the lower) contains the 2DEG layer. The role of the two parts of the device is different: the first leaf acts as a coupler of the incident radiation, whilst the second, lower leaf, is the active part, where the two-dimensional electrons are heated non-uniformly by the radiation. As a result, a voltage signal over the ends of the diode should be induced without application of any bias voltage.

To prove the principle of the operation and to understand the physics behind, we have studied two 2DEG bow-tie diodes of a different design. The main idea of this approach was to vary the 2DEG mobility as the electron heating is proportional to this parameter. The variation can be achieved by changing the spacer thickness or altering the temperature of the sample [41].

Initially, the devices were tested in a microwave field of $10 \mathrm{GHz}$ frequency. The samples were placed in the rectangular waveguide and illuminated with pulsed

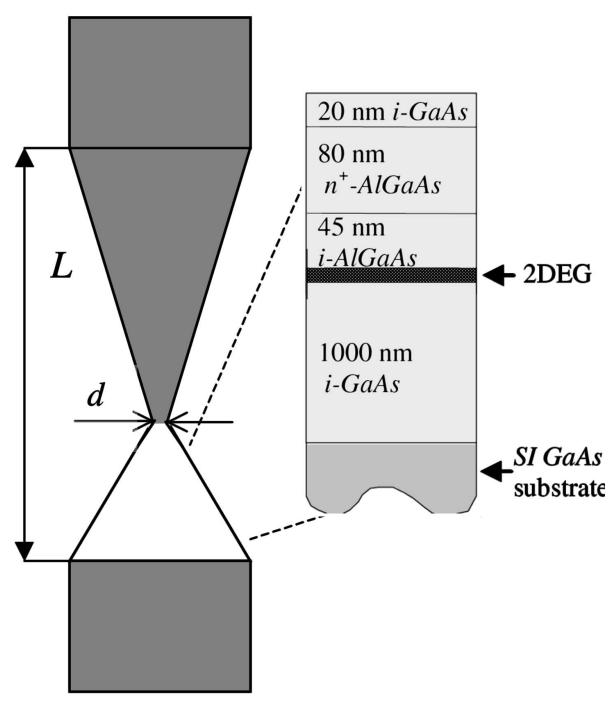

(a)

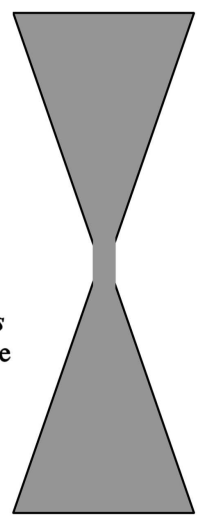

(b)
Fig. 11. (a) Schematic view of the 2DEG bow-tie diode. The devices are processed into mesas by wet etching. The length of the device is $500 \mu \mathrm{m}$, the width is $100 \mu \mathrm{m}$, while the length of the active part amounts to $50 \mu \mathrm{m}, L=300 \mu \mathrm{m}$. The structures are produced using a standard optical (when apex $d$ size is $12 \mu \mathrm{m}$, mesa depth is $2 \mu \mathrm{m}$ ) and an electron beam lithography (when apex $d$ size is 3 and $2 \mu \mathrm{m}$, the mesa depth is $300 \mathrm{~nm}$ ). Dark colour shows metallized part made by rapid annealing of $\mathrm{Au} / \mathrm{Ge} / \mathrm{Ni}$ alloy. (b) The shape of a conventional bow-tie antenna is also presented for comparison. Inset depicts the schematic design of the active part (light colour). Exact structure of the active part (from the top) for the studied different 2DEG- $\boldsymbol{A}$ and 2DEG- $\boldsymbol{B}$ diodes, respectively (bold font is used to underline the main differences in design): $20 \mathrm{~nm} i$-GaAs cap layer; $80 \mathrm{~nm} \mathrm{Si-doped}\left(10^{18} \mathrm{~cm}^{-3}\right)$ layer of $\mathrm{Al}_{0.25} \mathrm{Ga}_{0.75} \mathrm{As}$ and $60 \mathrm{~nm} \mathrm{Si}$-doped $\left(2 \cdot 10^{18} \mathrm{~cm}^{-3}\right)$ of $\mathrm{Al}_{0.3} \mathrm{Ga}_{0.7} \mathrm{As}$; undoped spacers, $45 \mathrm{~nm} \mathbf{A l}_{0.25} \mathbf{G a}_{0.75} \mathrm{As}$ and $10 \mathbf{~ n m ~} \mathbf{A l}_{0.3} \mathbf{G a}_{0.7} \mathbf{A s} ; 1000 \mathrm{~nm}$ and $600 \mathrm{~nm}$ of $i$-GaAs; twenty and six periods of $9 \mathrm{~nm} \mathrm{AlGaAs} / 1.5 \mathrm{~nm}-\mathrm{GaAs}$ layers; $0.5 \mu \mathrm{m}$ and $0.6 \mu \mathrm{m}$ of $i$-GaAs; semi-insulating substrate.

radiation of $2-5 \mu$ s duration and a repetition rate of $40 \mathrm{~Hz}$. The signal was recorded by an oscilloscope.

The results are depicted in Fig. 12, where voltagepower dependences of the bow-tie diodes 2DEG- $A$ and 2 DEG- $B$ at room and liquid nitrogen temperatures are given. It is seen that the signal in all investigated devices behaves linearly over two orders of magnitude of the microwave power. At powers exceeding $50 \mathrm{~mW}$, the non-monotonical character of the detected signal at $77 \mathrm{~K}$ has been observed in 2DEG- $A$ diode with a $12 \mu \mathrm{m}$ apex (similar behaviour is also found in all other samples, these data are omitted). We attribute it to the realspace transfer effects of hot electrons from the quantum well formed in GaAs at the interface to AlGaAs into the adjacent $\mathrm{AlGaAs}$ layer and vice versa. The decrease in temperature greatly increases the sensitivity of the device: it is around $0.3-0.4 \mathrm{~V} / \mathrm{W}$ at room temperature, while it reaches $20 \mathrm{~V} / \mathrm{W}$ at $77 \mathrm{~K}$ for $12 \mu \mathrm{m}$ 


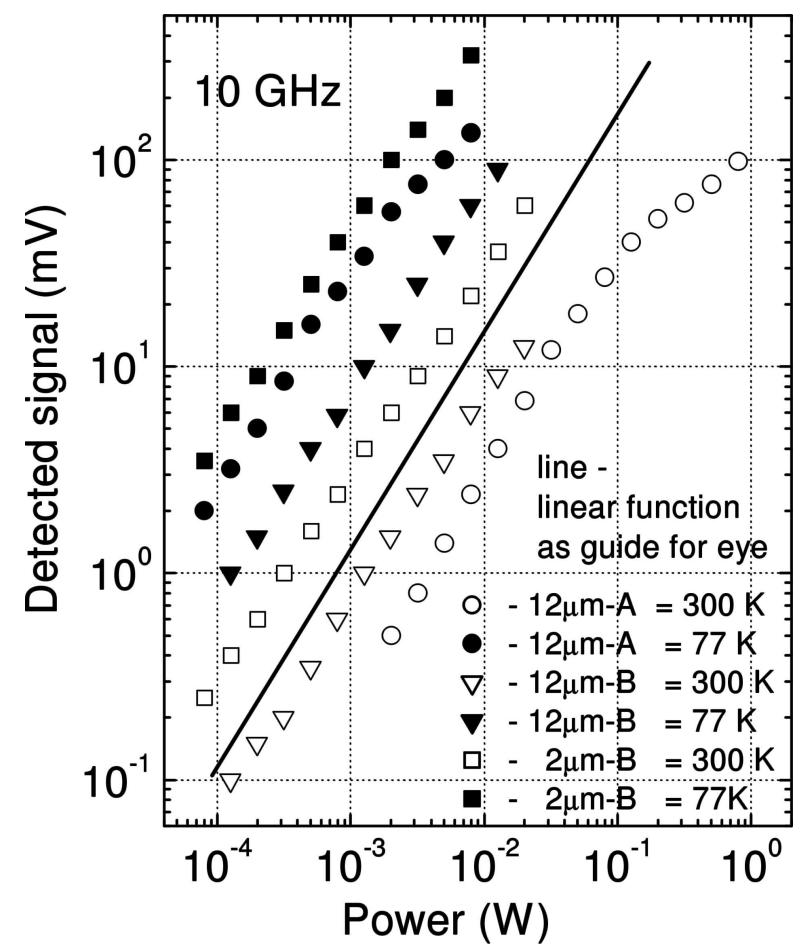

Fig. 12. Voltage-power characteristics of bow-tie diodes with 12 and $2 \mu \mathrm{m}$ apexes placed in $10 \mathrm{GHz}$ frequency radiation at room and liquid nitrogen temperatures. Sheet electron densities and mobilities at 300 and $77 \mathrm{~K}$ are, respectively: diode 2DEG- $A-5.5 \cdot 10^{11} \mathrm{~cm}^{-2}$ and $4700 \mathrm{~cm}^{2} /(\mathrm{V} \mathrm{s}), 1.9 \cdot 10^{11} \mathrm{~cm}^{-2}$ and $190600 \mathrm{~cm}^{2} /(\mathrm{V} \mathrm{s})$; diode 2DEG- $B-5.6 \cdot 10^{11} \mathrm{~cm}^{-2}$ and $8000 \mathrm{~cm}^{2} /(\mathrm{V} \mathrm{s}), 4.3 \cdot 10^{11} \mathrm{~cm}^{-2}$ and $116000 \mathrm{~cm}^{2} /(\mathrm{V} \mathrm{s})$.

apex diodes, i.e. the factor of increase is about 50 . Comparing this number with the relative increase in the electron mobility with temperature, one can infer that the latter effect is mainly responsible for the observed rise in the signal [42]. As a further confirmation of the effect, one can compare the devices having different spacer thickness, $45 \mathrm{~nm}$ (2DEG- $A$ ) and $10 \mathrm{~nm}$ (2DEG- $B$ ), and therefore resulting in electron mobilities of $4700 \mathrm{~cm}^{2} /(\mathrm{V} \mathrm{s})$ and $190600 \mathrm{~cm}^{2} /(\mathrm{V} \mathrm{s})$ for the first type and $8000 \mathrm{~cm}^{2} /(\mathrm{V} \mathrm{s})$ and $116000 \mathrm{~cm}^{2} /(\mathrm{V} \mathrm{s})$ for the second one in room and liquid nitrogen temperatures, respectively. One can see that the voltage sensitivity behaves similarly to the temperature variation case - its value is proportional to the mobility. More specifically, the ratio of electron mobilities in 2DEG- $B$ /2DEG- $A$ structures at room temperature is about 1.7 , while the relevant sensitivity ratio differs by a factor of $1.875(0.6 \mathrm{~V} / \mathrm{W}$ to $0.32 \mathrm{~V} / \mathrm{W})$. The same trend remains also at $77 \mathrm{~K}$ (see Fig. 12).

The values of voltage sensitivity at room temperature are of particular interest for the direct applications. In order to increase the sensitivity of the diode, we have chosen the design 2DEG- $B$ (due to the higher value of

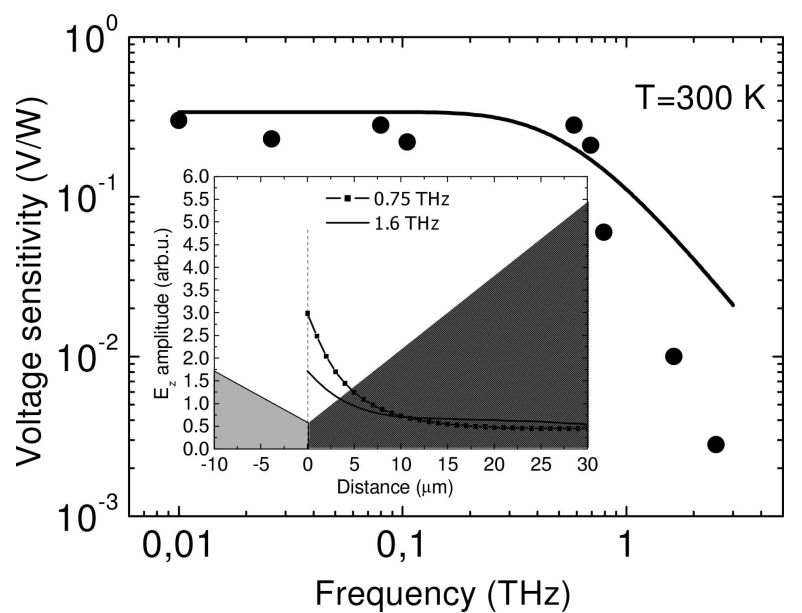

Fig. 13. Voltage sensitivity as a function of frequency within $\mathrm{GHz}-$ THz range for the 2DEG- $A$ bow-tie diode. Dark circles denote experimental data, solid line shows the fit using the phenomenological approach ([43] and references therein). Inset: distribution of the amplitude of electric field in the active part of the diode exposed to radiation of $0.75 \mathrm{THz}$ and $1.6 \mathrm{THz}$ frequencies. Calculations are made using three-dimensional FDTD method. Distance is taken from the narrowest part of the apex. The background of the inset is decorated schematically as the shape of the device.

the sensitivity at room temperature) and reduced the size of the apex down to $2 \mu \mathrm{m}$ keeping the other geometrical dimensions the same. One can note that in this case the detected signals are significantly larger than for the $12 \mu \mathrm{m}$ apex diodes at room temperature, and the sensitivity amounts to $2.5 \mathrm{~V} / \mathrm{W}$, which is nearly one order of magnitude higher compared to the diodes of with $12 \mu \mathrm{m}$ apex where it is about $0.32 \mathrm{~V} / \mathrm{W}$. The decrease in temperature down to $77 \mathrm{~K}$ allows one to increase the sensitivity up to nearly $40 \mathrm{~V} / \mathrm{W}$, i.e. close to a factor of 14.5 which corresponds to the change of 2DEG mobility. It is worth noting, however, that further decrease of the apex size down to $1 \mu \mathrm{m}-800 \mathrm{~nm}$ gives no increase in the sensitivity (data are not given here). We suppose that this can be associated with a weaker coupling of the microwave field into the active structure in this range of the apex width.

For practical implementation needs, it is very useful to know the detection bandwidth of the 2DEG bow-tie diodes at room temperature. To reach this aim the devices were studied using various sources of emission: magnetron/klystron generators (10-37 GHz), backward wave oscillators $(78-118 \mathrm{GHz})$, and an optically pumped molecular THz laser $(0.584-2.52 \mathrm{THz})$. In the latter case the signal was recorded by a lock-in amplifier. In all the experiments the incident electric field $E_{Z}$ was oriented along the diode.

The voltage sensitivity as a function of frequency is presented in Fig. 13. One can see that the detector ex- 
hibits very broad detection bandwidth ranging from microwaves up to terahertz frequencies (in this measurement between $10 \mathrm{GHz}$ and $0.8 \mathrm{THz}$ ) with nearly constant voltage sensitivity of around $0.3 \mathrm{~V} / \mathrm{W}$. The frequency plateau ends above $0.8 \mathrm{THz}$, at higher frequencies the sensitivity monotonically drops to the value of $3 \cdot 10^{-3} \mathrm{~V} / \mathrm{W}$ at $2.52 \mathrm{THz}$. It is evident that experimental data below $1 \mathrm{THz}$ fit well with phenomenological calculations ([43] and references therein) given here by the solid line. At higher frequencies the voltage sensitivity decreases, and the difference between the experiments and the theory appears. In case of phenomenological calculations, the decrease in the sensitivity value is defined by the carrier momentum relaxation time. It is seen that the experimental data are below the theoretical estimate. We suppose that the socalled antenna effects due to weaker coupling of the $\mathrm{THz}$ radiation to the active part of the device at higher frequencies are responsible for the observed peculiarity. The support for this attribution can be easily understood from the inset of the picture presenting distribution of the electric field amplitude in the diode. The simulations are done by three-dimensional FDTD method under illumination of the diode at 0.75 and 1.6 THz frequencies. The distance is taken from the narrowest part of the apex, and the background of the inset is decorated schematically as the shape of the device. One can see that the electric field is concentrated in the apex of the diode, and its amplitude decreases with the increase of the $\mathrm{THz}$ frequency.

One should note that the induced voltage signal depends linearly on the incident radiation power at all the studied frequencies illustrating the suitability of the diode for power measurements [44].

In the remaining part of the paper, we will focus ourselves to the sub-THz-THz part. As was demonstrated above, the inherent feature of the bow-tie devices is the plateau in voltage sensitivity versus frequency at $300 \mathrm{~K}$. The broadband sensing is still an issue in $\mathrm{THz}$ electronics, and, therefore, exploration for possibilities to increase the sensitivity at room temperature is of particular importance. We have applied the same ideology like in the previous case, i. e. we have reduced the apex size down to 3-2 $\mu \mathrm{m}$ and modelled the device operation using the same two, the phenomenological and the FDTD, approaches. The results of voltage sensitivity of 2DEG bow ties with apexes of 12 and $3 \mu \mathrm{m}$ [45] are given in Fig. 14. It is seen that the diode with the $3 \mu \mathrm{m}$ apex has the sensitivity by a factor of 1.5 larger compared to the $12 \mu \mathrm{m}$ apex device with the same geometry. The increase in sensitivity correlates with the

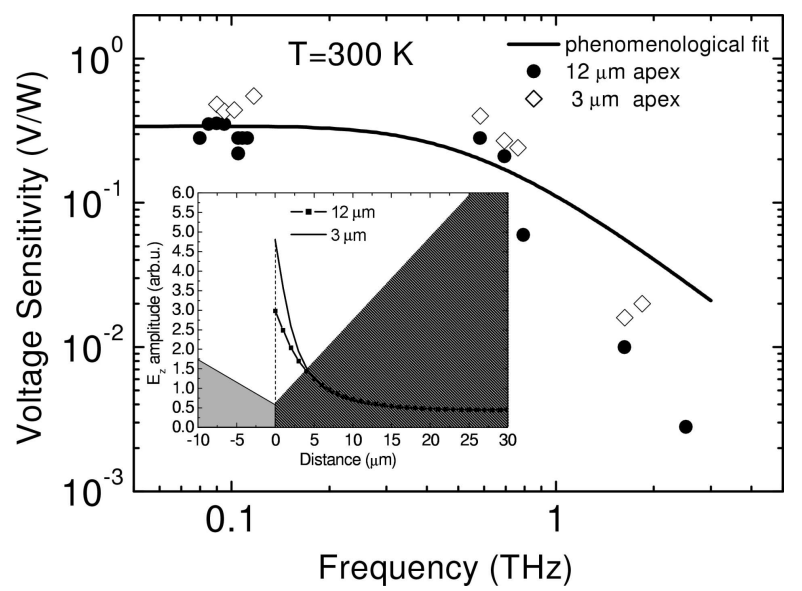

Fig. 14. Voltage sensitivity as a function of frequency within the THz range for the bow-tie 2DEG- $A$ diodes having different sizes of the apex. Circles and diamonds denote experimental data, solid line shows the fit using the phenomenological approach ([43] and references therein). Inset depicts distribution of the amplitude of electric field in the active part of the diode exposed to radiation of $0.75 \mathrm{THz}$ frequency for diodes with different sizes of the apex. Calculations are made using three-dimensional FDTD method. Distance is taken from the narrowest part of the apex. The background of the inset is decorated schematically as the shape of the device.

modelling of the distribution of the electric field amplitude performed at $0.75 \mathrm{THz}$ frequency (see inset of Fig. 14) - in the $3 \mu \mathrm{m}$ apex diode the amplitude of the field in the apex is larger by a factor of 1.6 than that in $12 \mu \mathrm{m}$ apex diode. Note that the electric field strength in the apex is almost 10 times higher than that away from the apex, and the same tendency is observed in both samples. Therefore, one can infer that the reduction of apex size is one of the possible ways to increase the voltage sensitivity of the device. To continue with the studies of the sensitivity improvement in $\mathrm{THz} / \mathrm{subTHz}$ range, we have tested the devices of 2 DEG- $B$ design with $2 \mu \mathrm{m}$ and $800 \mathrm{~nm}$ apexes previously used in $10 \mathrm{GHz}$ studies. As well as in microwaves, the sensitivity, for instance, at $0.693 \mathrm{THz}$ is found to be around $2 \mathrm{~V} / \mathrm{W}$ [46], and it is independent of the apex size. At frequencies above $1 \mathrm{THz}$, unfortunately, these diodes operate rather poorly. We relate this fact to a weak coupling of the $\mathrm{THz}$ radiation into the devices. To overcome this obstacle, one can, for example, mount the device on a silicon lens - this work is in progress now.

Finalizing this section, it is worth noting that some innovation in fabrication of the 2DEG bow-tie diodes removing the metallization of the leaf - allows producing a sample which is asymmetrically-necked and having a shape resembling the bulk silicon and germanium specimen used in the study of the bigradient effect $[47,48]$. Indeed, the experimentally obtained 
$I-V$ characteristics of asymmetrically-shaped structures with 2DEG at low temperatures, 4-100 K, are asymmetric, and this observation can be explained by the emergence of the two-dimensional bigradient effect [49].

\section{Conclusions}

In this paper, we have reviewed three approaches demonstrating impressive possibilities of modern semiconductor nanotechnology to fabricate new generation of compact devices for terahertz electronics needs. Firstly, as an example of compact emitter, we have described the principles of operation of THz QCLs and their specifics underlying the necessity to merge quantum mechanics in design and waveguiding to manage emission modes and to couple them out of the cavity. Further, we have presented two different types of sensors realizing compact $\mathrm{THz}$ detection schemes, also illustrating the need of unconventional confluence of different fields of physics by using semiconductor nanostructures - nanometric field effect transistors on the one hand, and asymmetric bow-tie diodes containing two-dimensional electron gas on the other one. The physics behind the first type of the detector - as an example of joining of plasma and semiconductor nanostructure physics - is the excitation of plasma waves by the external THz radiation, and these detectors can successfully be used for selective $\mathrm{THz}$ sensing tunable by the gate voltage. The second type of devices, the bowtie diodes - an example of a combination of semiconductor nanostructure physics and antennae approach relies on the non-uniform 2DEG heating in external high frequency fields and can be fruitfully employed for broadband detection in $\mathrm{GHz}-\mathrm{THz}$ frequencies.

The state of the art of the dominating compact solid state-based devices - both emitters and detectors - is summarized in Fig. 15. To illustrate the explicit insight and prevision by Juras Požela, his diagram, made nearly two decades ago, is also given for comparison.

\section{Acknowledgements}

We would like to sincerely thank many people, directly or indirectly involved in this study. We highly appreciate Karl Unterrainer and Gottfried Strasser (Vienna University of Technology) for involving one of us (V. T.) into quantum cascade laser topic and for encouraging the interests of our $\mathrm{THz}$ Atelier group (Vilnius) in this field of research; we are grateful to Steponas Ašmontas for showing the track to the bigradient effect

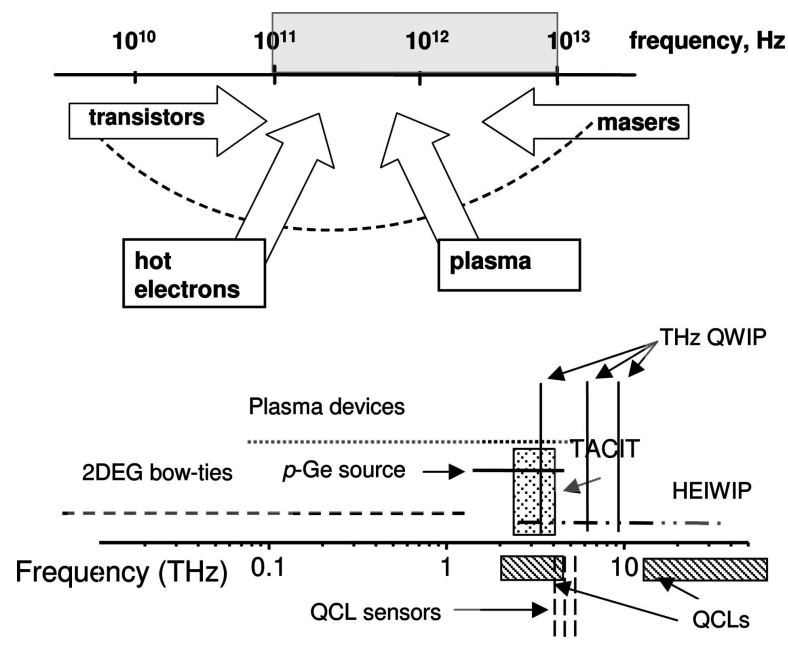

Fig. 15. Covering of the $\mathrm{THz}$ frequency range by various emitters and detectors based on solid state semiconductor structures and the prevision by Juras Požela taken from [1] (p. 248) for comparison. Solid state sources of THz emission: $p$-Ge emitter - operation range within 1.2-4 THz in magnetic fields [50]; QCLs data according to [10-12], [13-17], and [51]; plasma devices - emission from plasma waves in nanotransistors [31,32]; frequency - up to $5 \mathrm{THz}$. Solid state THz sensors: bow-tie diodes operating on hot carrier effects - according to [44-46]; TACIT - tunable antennacoupled intersubband terahertz - detector based on intraband transitions [52]; plasma devices - detection by plasma waves [24-28], frequency - up to $3.1 \mathrm{THz}$ [35]; QCL structures as THz detectors according to [19], THz QWIP - quantum well infrared photodetectors - operating on bound-to-continuum transitions [20,21] and [53]; HEIWIP - heterojunction interfacial workfunction internal photoemission - sensor $[54,55]$.

and the initial care in the creating the infrastructure of the laboratory. We are deeply indebted to Saulius Balakauskas and Robert Sachs (Frankfurt/M, Germany) for their kind help in preparing the bow-tie samples, as well as to Algirdas Sužiedèlis and Jonas Gradauskas for the assistance in the initial phase of the research. A lot of our sincere thanks go to Wai-Heng Chow, Paul Steenson, and Paul Harrison (Leeds, U. K.) for the tremendous help in using technological facilities of Nanotechnology Centre at the University of Leeds, to Sylvain Bollaert (Lille, France) for providing us the unique InGaAs / AlInAs nanotransistors, and Frederic Teppe (Montpellier, France) for valuable discussions on plasmonic experimental data. Also, we would like to express honest gratitude to Tomas Anbinderis, Pavel Anbinderis, and Aleksandras Narkūnas (Elmika Ltd, Vilnius) for valuable discussions on broadband $\mathrm{GHz}-$ $\mathrm{THz}$ detector issues and for the experimental data obtained using backward wave oscillators.

The quantum cascade laser activities are supported, in part, by European network POISE - "Physics of Intersubband Semiconductor Emitters", the research in plasma waves in nanometric transistors is partly 
sponsored by the European projects PRAMA - "Centre of Processing, Research and Application of Advanced Materials" - via the programme "Centres of Excellence" and GDR (Groupement De Recherche) on $\mathrm{THz}$ - "Semiconductor Sources and Detectors of $\mathrm{THz}$ Frequencies". The bow-tie sensor development is financed, in part, by NATO Science for Peace Programme under the contract SfP-978030 "Broad Band Detectors". The research conducted in Vilnius is also supported by the $\mathrm{THz}$ Atelier Group and is performed under the topic "Study of semiconductor nanostructures for terahertz technologies" (No. 144).

\section{References}

[1] J. Požela, Physics of High-Speed Transistors (Vilnius, Mokslas, 1989) [in Russian].

[2] A.Y. Cho and J.R. Arthur, Molecular beam epitaxy, Prog. Solid State Chem. 10, 157-191 (1975).

[3] J. Faist, F. Cappaso, D.L. Sivco, C. Sirtori, A.L. Hutchinson, and A.Y. Cho, Quantum cascade laser, Science 264, 553-556 (1994).

[4] F. Capasso, R. Paiella, R. Martini, R. Colombelli, C. Gmachl, T.L. Myers, M.S. Taubman, R.M. Williams, C.G. Bethea, K. Unterrainer, H.Y. Hwang, D.L. Sivco, A.Y. Cho, A.M. Sergent, H.C. Liu, and E.A. Whittaker, Quantum cascade lasers: Ultrahigh-speed operation, optical wireless communication, narrow linewidth, and far-infrared emission, IEEE J. Quantum Electron. 38, 511-532 (2002).

[5] J. Faist, D. Hofstetter, M. Beck, T. Aellen, M. Rochat, and S. Blaser, Bound-to-continuum and two-photon resonance quantum cascade lasers for high duty cycle, high-temperature operation, IEEE J. Quantum Electron. 38, 533-546 (2002).

[6] J. Faist, C. Gmachl, M. Striccoli, C. Sirtori, and F. Capasso, Quantum cascade disk lasers, Appl. Phys. Lett. 69, 2456-2458 (1996).

[7] C. Gmachl, F. Capasso, E.E. Narimanov, J.U. Nöckel, A. Douglas Stone, J. Faist, D.L. Sivco, and A.Y. Cho, High-power directional emission from microlasers with chaotic resonators, Science 280, 1556-1564 (1998).

[8] A. Tredicucci, C. Gmachl, F. Capasso, A. L. Hutchinson, D.L. Sivco, and A.Y. Cho, Single-mode surfaceplasmon laser, Appl. Phys. Lett. 76, 2164-2166 (2000).

[9] R. Colombelli, K. Srinivasan, M. Troccoli, O. Painter, C.F. Gmachl, D.M.Tennant, A.M. Sergent, D.L. Sivco, A.Y. Cho, and F. Capasso, Quantum cascade surfaceemitting photonic crystal laser, Science 302, 1374 1377 (2003).

[10] R. Köhler, A. Tredicucci, F. Beltram, H.E. Beere, E.H. Linfeld, A.G. Davies, D.A. Ritchie, R.C. Iotti, and F. Rossi, Terahertz semiconductor heterostructure laser, Nature (London) 417, 156-159 (2002).

[11] B.S. Williams, H. Callebaut, S. Kumar, Q. Hu, and J.L. Reno, 3.4-THz quantum cascade laser based on LO-phonon scattering for depopulation, Appl. Phys. Lett. 82, 1015-1017 (2003).

[12] C. Sirtori, C. Gmachl, F. Capasso, J. Faist, D.L. Sivco, A.L. Hutchinson, and A.Y. Cho, Long-wavelength (8$11.5 \mu \mathrm{m}$ ) semiconductor lasers with waveguides based on surface plasmons, Opt. Lett. 23, 1366-1368 (1998).

[13] B.S. Williams, S. Kumar, H. Callebaut, Q. Hu, and J.L. Reno, 3.0 THz $(\lambda=100 \mu \mathrm{m})$ quantum-cascade laser using metal waveguide for mode confinement, Appl. Phys. Lett. 83, 2124-2126 (2003).

[14] B.S. Williams, S. Kumar, Q. Hu, and J.L. Reno, Resonant-phonon terahertz quantum-cascade laser operating at $2.1 \mathrm{THz}(\lambda \sim 141 \mu \mathrm{m})$, Electron. Lett. 40, 431-432 (2004).

[15] S. Kumar, B.S. Williams, S. Kohen, Q. Hu, and J.L. Reno, Continuous-wave operation of terahertz quantum-cascade lasers above liquid-nitrogen temperature, Appl. Phys. Lett. 84, 2494-2496 (2004).

[16] B.S. Williams, S. Kumar, Q. Hu, and J.L. Reno, Operation of terahertz quantum-cascade lasers at $164 \mathrm{~K}$ in pulsed mode and at $117 \mathrm{~K}$ in continuous-wave mode, Opt. Express 13, 3331-3339 (2005).

[17] G. Fasching, A. Benz, K. Unterrainer, R. Zobl, A.M. Andrews, T. Roch, W. Schrenk, and G. Strasser, Terahertz microcavity quantum-cascade lasers, Appl. Phys. Lett. 87, 211112-1-3 (2005).

[18] V. Tamošiūnas, R. Zobl, J. Ulrich, K. Unterrainer, R. Colombelli, C. Gmachl, K. West, L. Pfeiffer, and F. Capasso, Terahertz quantum cascade lasers in a magnetic field, Appl. Phys. Lett. 83, 3873-3875 (2003).

[19] D. Hofstetter, M. Beck, and J. Faist, Quantum-cascadelaser structures as photodetectors, Appl. Phys. Lett. 81, 2683-2685 (2002).

[20] M. Graf, G. Scalari, D. Hofstetter, J. Faist, H. Beere, E. Linfield, D. Ritchie, and G. Davies, Terahertz range quantum well infrared photodetector, Appl. Phys. Lett. 84, 475-477 (2004).

[21] H. Luo, H.C. Liu, C.Y. Song, and Z.R. Wasilewski, Background-limited terahertz quantum-well photodetector, Appl. Phys. Lett. 86, 231103-1-3 (2005).

[22] M. Dyakonov and M.S. Shur, Shallow water analogy for a ballistic field effect transitor: New mechanism of plasma wave generation by dc current, Phys. Rev. Lett. 71, 2465-2468 (1993).

[23] W. Knap, Y. Deng, S. Rumyantsev, J.-Q. Lü, M.S. Shur, C.A. Saylor, and L.C. Brunel, Resonant detection of subterahertz radiation by plasma waves in a submicron field-effect transistor, Appl. Phys. Lett. 80, 3433-3435 (2002).

[24] W. Knap, Y. Deng, S. Rumyantsev, and M.S. Shur, Resonant detection of subterahertz and terahertz radia- 
tion by plasma waves in submicron field-effect transistors, Appl. Phys. Lett. 81, 4637-4639 (2002).

[25] W. Knap, V. Kachorovskii, Y. Deng, S. Rumyantsev, J.-Q. Lü, R. Gaska, M.S. Shur, G. Simin, X. Hu, M. Asif Khan, C.A. Saylor, and L.C. Brunel, Nonresonant detection of terahertz radiation in field effect transistors, J. Appl. Phys. 91, 9346-9353 (2002).

[26] X.G. Peralta, S.J. Allen, M.C. Wanke, N.E. Harff, J.A. Simmons, M.P. Lilly, J.L. Reno, P.J. Burke, and J.P. Eisenstein, Terahertz photoconductivity and plasmon modes in double-quantum-well field-effect transistors, Appl. Phys. Lett. 81, 1627-1629 (2002).

[27] E.A. Shaner, M. Lee, M.C. Wanke, A.D. Grine, J.L. Reno, and S.J. Allen, Single-quantum-well grating-gated terahertz plasmon detectors, Appl. Phys. Lett. 87, 193507-1-3 (2005).

[28] Y.M. Meziani, J. Lusakowski, N. Dyakonova, W. Knap, D. Seliuta, E. Širmulis, J. Devenson, G. Valušis, F. Boeuf, and T. Skotnicki, Non resonant response of terahertz radiation by submicron CMOS transistors, IEICE Trans. Electronics (2006, in press).

[29] F. Teppe, W. Knap, D. Veksler, M.S. Shur, A.P. Dmitriev, V.Yu. Kachorovskii, and S. Rumyantsev, Room-temperature plasma waves resonant detection of sub-terahertz radiation by nanometer fieldeffect transistor, Appl. Phys. Lett. 87, 052107-1-3 (2005).

[30] F. Teppe, D. Veksler, V.Yu. Kachorovskii, A.P. Dmitriev, X. Xie, X.-C. Zhang, S. Rumyantsev, W. Knap, and M.S. Shur, Plasma wave resonant detection of femtosecond pulsed terahertz radiation by a nanometer field-effect transistor, Appl. Phys. Lett. 87, 022102-1-3 (2005).

[31] W. Knap, J. Lusakowski, T. Parenty, S. Bollaert, A. Cappy, V.V. Popov, and M.S. Shur, Terahertz emission by plasma waves in $60 \mathrm{~nm}$ gate high electron mobility transistors, Appl. Phys. Lett. 84, 2331-2333 (2004).

[32] J. Lusakowski, W. Knap, N. Dyakonova, L. Varani, J. Mateos, T. Gonzalez, Y. Roelens, S. Bollaert, and A. Cappy, Voltage tunable terahertz emission from a ballistic nanometer InGaAs / InAlAs transistor, J. Appl. Phys. 97, 064307-1-7 (2005).

[33] Y. Deng, R. Kersting, J. Xu, R. Ascazubi, X.C. Zhang, M.S. Shur, R. Gaska, G.S. Simin, M.A. Khan, and V. Ryzhii, Millimeter wave emission from GaN high electron mobility transistor, Appl. Phys. Lett. 84, 7072 (2004).

[34] M. Dyakonov and M. Shur, Detection, mixing, and frequency multiplication of terahertz radiation by twodimensional electronic fluid, IEEE Trans. Electron Devices 43, 380-387 (1996).

[35] A. El Fatimy, F. Teppe, N. Dyakonova, W. Knap, D. Seliuta, G. Valušis, A. Shchepetov, V. Roelens, S. Bollaert, A. Cappy, and S. Rumyantsev, Resonant and voltage tunable terahertz detection in In-
GaAs / InP-nanometric transistors, Appl. Phys. Lett. (submitted).

[36] D.B. Rutledge and M.S. Muha, Imaging antenna arrays, IEEE Trans. Antennas Propag. 30, 535-540 (1982).

[37] R.C. Compton, R.C. McPhedran, Z. Popovic, G.M. Rebeiz, P.P. Tong, and D.B. Rutledge, Bow-tie antennas on a dielectric half-space: Theory and experiment, IEEE Trans. Antennas Propag. 35, 622-630 (1987).

[38] H. Drexler, J.S. Scott, S.J. Allen, K.L. Campman, and A.C. Gossard, Photon-assisted tunneling in a resonant tunneling diode: Stimulated emission and absorption in the THz range, Appl. Phys. Lett. 67, 2816-2818 (1995).

[39] A.J. Kreisler and A. Gaugue, Recent progress in high-temperature superconductor bolometric detectors: From the mid-infrared to the far-infrared (THz) range, Supercond. Sci. Technol. 13, 1235-1245 (2000).

[40] Y.C. Shen, P.C. Upadhya, H.E. Beere, E.H. Linfield, A.G. Davies, I.S. Gregory, C. Baker, W.R. Tribe, and M.J. Evans, Generation and detection of ultrabroadband terahertz radiation using photoconductive emitters and receivers, Appl. Phys. Lett. 85, 164-166 (2004).

[41] K. Hirakawa and H. Sakaki, Mobility of the twodimensional electron gas at selectively doped $n$-type AlGaAs/GaAs heterojunctions with controlled electron concentrations, Phys. Rev. B 33, 8291-8303 (1986).

[42] A. Juozapavičius, L. Ardaravičius, A. Sužiedèlis, A. Kozič, J. Gradauskas, J. Kundrotas, D. Seliuta, E. Širmulis, S. Ašmontas, G. Valušis, H.G. Roskos, and K. Köhler, Microwave sensor based on modulation-doped GaAs/AlGaAs structure, Semicond. Sci. Technol. 19, S436-S439 (2004).

[43] A. Sužiedèlis, S. Ašmontas, J. Gradauskas, G. Valušis, and H.G. Roskos, Giga- and terahertz frequency band detector based on an asymmetrically-necked $n-n^{+}$. GaAs planar structure, J. Appl. Phys. 93, 3034-3038 (2003).

[44] D. Seliuta, E. Širmulis, V. Tamošiūnas, S. Balakauskas, S. Ašmontas, A. Sužiedėlis, J. Gradauskas, G. Valušis, A. Lisauskas, H.G. Roskos, and K. Köhler, Detection of terahertz/sub-terahertz radiation by asymmetrically-shaped 2DEG layers, Electron. Lett. 40, 631-632 (2004).

[45] G. Valušis, D. Seliuta, V. Tamošiūnas, E. Širmulis, S. Balakauskas, J. Gradauskas, A. Sužiedèlis, S. Ašmontas, T. Anbinderis, A. Narkūnas, I. Papsujeva, A. Lisauskas, H.G. Roskos and K. Köhler, Broad band THz sensing by 2DEG bow-tie-type diodes, Acta Phys. Pol. A 107, 184-187 (2005).

[46] D. Seliuta, E. Širmulis, V. Tamošiūnas, S. Ašmontas, A. Sužiedèlis, J. Gradauskas, G. Valušis, 
P.D. Steenson, W.-H. Chow, P. Harrison, A. Lisauskas, H.G. Roskos, and K. Köhler, THz/subTHz detection by asymmetrically-shaped bow-tie-type diodes containing a 2DEG layer, in: Proc. 27th Intern. Conf. Physics on Semiconductors ICPS-27, Flagstaff, Arizona, USA, 26-30 July 2004, eds. J. Menéndez and C.G. Van de Walle, AIP Conference Proceedings, Vol. 772 (Two Volume Print, 1697 p.) pp. 1204-1205 (2005).

[47] S. Ašmontas, K. Požela, and K. Repšas, Investigation of $I-V$ characteristics of $\mathrm{Ge}$ and $\mathrm{Si}$ asymmetrically necked samples, Lietuvos Fizikos Rinkinys 15, 249258 (1975).

[48] S. Ašmontas, Study of electron heating by nonuniform electric fields in $n$-Si, Phys. Status Solidi A 31, 409415 (1975).

[49] S. Ašmontas, A. Juozapavičius, D. Seliuta, E. Širmulis, V. Tamošiūnas, G. Valušis, and K. Köhler Inplane shaped GaAs / AlGaAs modulation-doped structures: Physics and applications for THz / subTHz sensing, in: Trends in Semiconductor Research, ed. T.B. Elliot (Nova Science Publishers, Inc., New York, 2005) pp. 59-80.
[50] D.R. Chamberlin, E. Bründermann, and E.E. Haller, Narrow linewidth intervalence-band emission from germanium terahertz lasers, Appl. Phys. Lett. 83, 3-5 (2003).

[51] C. Worrall, J. Alton, M. Houghton, S. Barbieri, H.E. Beere, D. Ritchie, and C. Sirtori, Continuous wave operation of a superlattice quantum cascade laser emitting at 2 THz, Opt. Express 14, 171-181 (2006).

[52] C.L. Cates, G. Briceno, M.S. Sherwin, K.D. Maranowski, C. Campman, and A.C. Gossard, A concept of a tunable antenna-coupled intersubband terahertz detector, Physica E 2, 463-647 (1998).

[53] C. Liu, C.Y. Song, A.J. SpingThorpe, and J.C. Cao, Terahertz quantum well photodetector, Appl. Phys. Lett. 84, 4068-4070 (2004).

[54] D.G. Esaev, M.B. M.Rinzan, S.G. Matsik, and A.G.U. Perera, Design and optimization of GaAs/AlGaAs heterojunction infrared detectors, J. Appl. Phys. 96, 4588-4597 (2004).

[55] M.B.M. Rinzan, A.G.U. Perera, S.G. Matsik, H.C. Liu, Z.R. Wasilewski, and M. Buchanan, AlGaAs emitter/GaAs barrier terahertz detector with a $2.3 \mathrm{THz}$ threshold, Appl. Phys. Lett. 86, 071112-1-3 (2005).

\title{
NAUJOS KRYPTYS TERAHERCINĖJE ELEKTRONIKOJE
}

\author{
V. Tamošiūnas ${ }^{a}$, D. Seliuta ${ }^{a}$, A. Juozapavičius ${ }^{\text {a }}$, E. Širmulis ${ }^{a}$, G. Valušis ${ }^{a}$, A. El Fatimy ${ }^{b}$, Y. Meziani $^{\text {b }}$, \\ N. Dyakonova ${ }^{\text {b }}$, J. Lusakowski ${ }^{\text {b }}$, W. Knap ${ }^{\text {b }}$, A. Lisauskas ${ }^{\text {c }}$, H.G. Roskos ${ }^{\text {c }}$, K. Köhler ${ }^{\text {d }}$ \\ ${ }^{a}$ Puslaidininkiu fizikos institutas, Vilnius, Lietuva \\ b 2-as Monpeljè universitetas, Monpeljè, Prancūzija \\ ${ }^{\mathrm{c}}$ Johano Volfgango Gètès universitetas, Frankfurtas prie Maino, Vokietija \\ ${ }^{\mathrm{d}}$ Fraunhoferio taikomosios kietojo kūno fizikos institutas, Freiburgas, Vokietija
}

\section{Santrauka}

Apžvelgiamos trys naujos terahercinès elektronikos kryptys, susijusios su mažų matmenų prietaisu kūrimu, pasitelkiant šiuolaikinès puslaidininkinès nanotechnologijos galimybes.

Terahercinių (1 THz yra $10^{12} \mathrm{~Hz}$ ) dažnių ruožas, apimantis dažniu juostą nuo 0,1 iki $10 \mathrm{THz}$, elektromagnetinių bangų skalèje glūdi tarp mikrobangų ir infraraudonosios srities, t.y. tarp klasikiniais krūvininkų pernašos dèsniais aprašomos elektronikos ir kvantinès mechanikos taisyklemis grindžiamos fotonikos. Taigi, ši sritis yra tarsi savotiškas ,tiltas“, jungiantis klasikini ir kvantini fizikos pasaulius, ir būtent tai daro terahercinès elektronikos prietaisu kūrimą gana savitą ir subtilų, nes reikia ieškoti labai savitų fizikinių ir technologinių sprendimų, talpinančių ir derinančių gana skirtingas fizikines koncepcijas.

Pateikiami ir aprašyti trys tokių netradiciniu sprendimu pavyzdžiai, sukurti panaudojant šiuolaikinès molekulinès epitaksijos, fotolitografijos bei elektroninès litografijos pasiekimus. Pirmasis jų, kvantinis kaskadinis lazeris, skirtas THz spinduliuotès emisijai, jungia savyje kvantmechaniniais skaičiavimais pagrịstą sluoksnių sandarą bei bangolaidžių fizikos principais paremtą emisijos modų sklidimo reguliavimą bei jų nuostolių rezonatoriuje mažinimą. Antrasis prietaisas - puslaidininkinis lauko tranzistorius su submikroninio ilgio sklende - yra tarsi plazmos fizikos bei puslaidininkių nanostruktūrų fizikos „lydinys“; pademonstruota, jog jis gali būti sẻkmingai pritaikomas atrankiai (selektyviai) THz spinduliuotès detekcijai, kurios dažninė charakteristika gali būti keičiama sklendès įtampa. Trečiasis įtaisas - peteliškès formos asimetrinis diodas su dvimačiais elektronais - ,atstovauja“ puslaidininkių nanostruktūrų fizikos ir antenos principu „,sujungimo“ koncepcijai ir yra skirtas plačiajuostei $\mathrm{GHz}-\mathrm{THz}$ dažnių ruožo detekcijai kambario temperatūroje.

Taip pat pateikiami bei palyginami ir kiti naujausi ịvairiais fizikiniais principais veikiančių $\mathrm{THz}$ dažnių ruožo kietakūnių emiterių bei jutikliu duomenys. 